\title{
Expression of Glucose Transporters 1 and 3 in Metastatic and Non-Metastatic Lower Lip Squamous Cell Carcinoma
}

\author{
Clarissa Favero Demeda ${ }^{1}$, Cyntia Helena Pereira de Carvalho², Ana Rafaela \\ Luz de Aquino ${ }^{3}$, Cassiano Francisco Weege Nonaka ${ }^{4}$, Lélia Batista de Souza ${ }^{1}$, \\ Leão Pereira Pinto ${ }^{1}$
}

\author{
'Department of Oral Pathology, \\ UFRN - Federal University of Rio \\ Grande do Norte, Natal, RN, Brazil \\ ${ }^{2}$ Department of Dentistry, UFCG \\ - Federal University of Campina \\ Grande, Patos, PB, Brazil \\ ${ }^{3}$ Department of Dentistry, UFRN - \\ Federal University of Rio Grande \\ do Norte, Natal, RN, Brazil \\ ${ }^{4}$ Department of Dentistry, \\ State University of Paraiba, \\ Campina Grande, PB, Brazil
}

Correspondence: Leão Pereira Pinto, Avenida Senador Salgado Filho, 1787, Lagoa Nova, 59056-000 Natal, RN, Brasil. Tel: +55-84-3215-4138. \begin{abstract}
e-mail: Ip.pinto@hotmail.com
\end{abstract}
\begin{abstract}
This study aimed to evaluate the immunoexpression of glucose transporters 1 (GLUT-1) and 3 (GLUT-3) in metastatic and non-metastatic lower lip squamous cell carcinoma (LLSCC). Twenty LLSCCs with regional nodal metastasis and 20 LLSCCs without metastasis were selected. The distribution of staining and the percentage of GLUT-1 and GLUT-3 staining in each tumor core and at the deep invasive front were assessed. Most tumors (70\%) exhibited peripheral staining for GLUT-1 in nests, sheets and islands of neoplastic cells, whereas predominantly central staining was observed for GLUT-3 (72.5\%). A high percentage of GLUT-1-positive cells was observed at the deep invasive front and in the tumor core of metastatic and non-metastatic tumors ( $p>0.05$ ). The percentage of GLUT-1positive cells was much higher than that of GLUT-3-positive cells both in the deep invasive front $(p<0.001)$ and in the tumor core $(p<0.001)$ of LLSCCs. No significant differences in the percentage of GLUT-1- and GLUT-3-positive cells were observed according to nodal metastasis, clinical stage or histological grade of malignancy $(p>0.05)$. In conclusion, the results of the present study suggest an important role of GLUT-1 in glucose uptake in LLSCCs, although this protein does not seem to be involved in the progression of these tumors. On the other hand, GLUT-3 expression may represent a secondary glucose uptake mechanism in LLSCCs.
\end{abstract}

\section{Introduction}

Squamous cell carcinoma is the most common malignancy in the lower lip (1). Although lower lip squamous cell carcinoma (LLSCC) is slow growing, up to $29 \%$ of tumors develop metastases to the cervical lymph nodes (2). Patients who develop late cervical metastases have a poor prognosis, with a 5 -year survival rate of only $25 \%$ to $50 \%$ (3).

Biologically, growing malignant tumors require the formation of blood vessels to increase respiration rates and nutrient absorption (4). However, angiogenesis does not accompany the growth of neoplastic cells, a fact resulting in areas of hypoxia in the tumor $(5,6)$. The neoplastic cells then undergo changes in order to adapt to and survive under these conditions, favoring invasion and metastases. During this process of adaptation, malignant neoplastic cells increase the uptake and metabolism of glucose $(5,7,8)$.

The regulation of the expression of glucose transporter proteins plays a critical role in the supply of glucose and other hexoses to metabolically active cells (7). Important proteins of this group are glucose transporters 1 (GLUT-1) and 3 (GLUT-3). Overexpression of these two proteins has been demonstrated in different malignant tumors such as esophageal, breast, and ovarian carcinomas $(7,9)$. In most of these cancers, elevated expression levels of these proteins have been associated with unfavorable clinical outcomes $(7,9)$. The few studies on oral squamous cell carcinomas (OSCCs) have shown an association between the overexpression of GLUT-1 and the presence of lymph node metastases (10-12), episodes of recurrence $(10,13)$, and low patient survival $(4,13,14)$. With respect to GLUT-3, Ayala et al. (15) found that the expression of this protein was associated with an advanced clinical stage of OSCC and lower disease-free survival rates.

Despite the large number of studies investigating the role of GLUTs in the development and progression of different human cancers, a search of the Pubmed database identified no reports on the expression of GLUT- 1 and -3 in LLSCC. Therefore, the objective of the present study was to evaluate the immunoexpression of GLUT- 1 and GLUT- 3 in metastatic and non-metastatic LLSCCs and its association with TNM stage and histological grade of malignancy.

\section{Material and Methods}

Forty cases of LLSCC, obtained from the files of Dr. Luiz Antônio Hospital, Natal, RN, Brazil, were selected for this study. The specimens were divided into two groups: a non-metastatic group consisting of 20 cases of LLSCC without regional lymph node metastasis, and a metastatic group consisting of 20 cases of LLSCC with regional lymph 
node metastasis. Information regarding the presence or absence of regional lymph node metastasis and clinical staging (TNM) was collected from the patient records. The study was approved by the Research Ethics Committee of Dr. Luiz Antônio Hospital, Natal, RN, Brazil.

Sections $(5 \mu \mathrm{m})$ were cut from paraffin-embedded tissue blocks, deparaffinized, and stained with hematoxylin and eosin for histological examination. The histological grade of malignancy was established for each case of LLSCC in a blind fashion by two observers. The tumors were graded as well-differentiated, moderately differentiated, and poorly differentiated according to World Health Organization (WHO) criteria (16).

In addition, the histological grade of malignancy at the tumor-host interface was established using the system proposed by Bryne (17), in which scores are attributed to the following parameters: degree of keratinization, nuclear pleomorphism, pattern of invasion, and inflammatory infiltrate. These scores are summed to provide a total malignancy score. Cases with a total score $\leq 8$ were classified as low-grade malignancy and those with a total score $>8$ were classified as high-grade malignancy according to the method adopted by Silveira et al. (18).

\section{Immunohistochemistry}

For immunohistochemical study, 3- $\mu \mathrm{m}$-thick sections were cut from paraffin-embedded tissue blocks. The sections were deparaffinized and immersed in 3\% hydrogen peroxide to block endogenous peroxidase activity. Next, the sections were washed in phosphate-buffered saline (PBS). The antigen retrieval procedure, antibody dilution, and clone type for GLUT-1 and -3 are shown in Table 1. After treatment with normal serum, the sections were incubated with the primary antibodies in a moist chamber. The tissue sections were then washed twice in PBS and treated with a polymer-based complex (Advance ${ }^{\mathrm{TM}} \mathrm{HRP}$; Dako, Carpinteria, CA, USA) at room temperature to bind the primary antibodies. Peroxidase activity was visualized by immersing the sections in diaminobenzidine (Liquid DAB+ Substrate, Dako), resulting in a brown reaction product. Finally, the sections were counterstained with Mayer hematoxylin and coverslipped. Erythrocytes present in each section served as internal positive control for anti-GLUT-1 antibody, and inflammatory cells of the adjacent tumor were used as internal positive control for anti-GLUT-3 antibody. As negative control, the samples were treated as described above, except that the primary antibody was replaced with a solution of bovine serum albumin in PBS.

\section{Analysis of Immunostaining}

Immunohistochemical analysis was performed by two observers in a blind fashion by two observers under an Olympus CX41 light microscope (Olympus Co., Tokyo, Japan). Expression of GLUT-1 and GLUT-3 was analyzed only in neoplastic epithelial cells.

The immunoexpression of GLUT- 1 and -3 was evaluated quantitatively using an adaptation of the method proposed by Ohba et al. (8). Five fields in the tumor core and at the deep invasive front that contained the largest number of immunostained cells were identified by light microscopy. Digital images of these five microscopic fields $(\times 200$ magnification) were acquired with an Olympus EVOLT E-330 digital camera (Olympus $\mathrm{C}_{0}$.) and transferred to the Image $J^{\circledR}$ software (National Institute of Mental Health, Bethesda, MD, USA). The number of positive and negative cells was determined in each field and the percentage of cells exhibiting cytoplasmic and/or membrane staining for GLUT-1 and GLUT-3 was calculated for each case.

The pattern of GLUT- 1 and GLUT- 3 staining was evaluated throughout the tumor at magnifications of $40 x$ and 200x. The cases were assigned to one of the following groups based on the predominant pattern of staining in nests, sheets and islands of neoplastic cells: predominantly central staining, predominantly peripheral staining, and similar staining in central and peripheral areas.

\section{Statistical Analysis}

The results were analyzed statistically using the Statistical Package for the Social Sciences (version 17.0; SPSS Inc., Chicago, IL, USA). For clinical staging, stages I and II were combined into one group and stages III and IV into another group. Similarly, for histological grading of malignancy, moderately and poorly differentiated tumors were combined into one group and compared to welldifferentiated tumors. The percentage of GLUT-1- and GLUT-3-immunopositive cells in the tumor core and at the tumor front was compared by the non-parametric Mann-Whitney test and the Wilcoxon signed rank test. Spearman's correlation test was used to determine possible correlations between the percentages of GLUT-1- and

Table 1. Catalog number, specificity, company, dilution, antigen retrieval and incubation of the primary antibodies

\begin{tabular}{lccccc}
\hline Catalog number & Specificity & Company & Dilution & Antigen retrieval & Incubation \\
\hline GTX15309 & GLUT-1 & GeneTex Inc., San Antonio, TX, USA & $1: 400$ & Citrate, pH 6.0 Pascal, 121 ${ }^{\circ} \mathrm{C}, 3 \mathrm{~min}$ & $60 \mathrm{~min}$ \\
GTX15311 & GLUT-3 & GeneTex Inc., San Antonio, TX, USA & $1: 400$ & Citrate, pH 6.0 Pascal, 121 ${ }^{\circ} \mathrm{C}, 3 \mathrm{~min}$ & $60 \mathrm{~min}$ \\
\hline
\end{tabular}


GLUT-3-immunopositive cells. A level of significance of $5 \%(p<0.05)$ was adopted for all tests.

\section{Results}

\section{Clinical and Morphological Analysis}

Regarding clinical stage, five (12.5\%) cases were classified as stage I, $13(32.5 \%)$ as stage II, 11 (27.5\%) as stage III, and $11(27.5 \%)$ as stage IV. Histological grading of malignancy proposed by the WHO classified 12 (30\%) cases as well-differentiated, $21(52.5 \%)$ as moderately differentiated, and $7(17.5 \%)$ as poorly differentiated. Twenty-two (55\%) cases were classified as low-grade malignancy at the tumor invasive front and 18 cases (45\%) as high-grade malignancy.

Most metastatic LLSCCs were classified as high-grade malignancy $(70 \%)$ or moderately/poorly differentiated tumors (90\%) ( $p=0.004$ and $p=0.014$, respectively). Most patients in stages III and IV (63.6\%) had high-grade malignancy tumors $(p=0.012)$. Similarly, most moderately/

Table 2. Median percentages of positivity for GLUT-1 and GLUT-3 in the deep invasive front and in the tumor core of lower lip squamous cell carcinomas, and their differences according to clinicopathologic characteristics

\begin{tabular}{|c|c|c|c|c|}
\hline \multirow{2}{*}{ Characteristics } & \multicolumn{2}{|c|}{ GLUT-1 } & \multicolumn{2}{|c|}{ GLUT-3 } \\
\hline & Median & $\mathrm{p}$ & Median & $\mathrm{p}$ \\
\hline \multicolumn{5}{|l|}{ Deep invasive front } \\
\hline \multicolumn{5}{|l|}{ Nodal metastasis } \\
\hline Present & 97.79 & 0.372 & 23.98 & 0.482 \\
\hline Absent & 96.19 & & 26.88 & \\
\hline \multicolumn{5}{|l|}{ Clinical staging } \\
\hline Stages $1 / 11$ & 95.55 & 0.341 & 26.62 & 0.892 \\
\hline Stages 111/ IV & 97.79 & & 26.54 & \\
\hline \multicolumn{5}{|l|}{ Histologic grading } \\
\hline Low grade & 96.85 & 0.447 & 26.74 & 0.384 \\
\hline High grade & 97.02 & & 21.64 & \\
\hline \multicolumn{5}{|l|}{ Tumor core } \\
\hline \multicolumn{5}{|l|}{ Nodal metastasis } \\
\hline Present & 96.43 & 0.903 & 19.05 & 0.499 \\
\hline Absent & 96.30 & & 30.34 & \\
\hline \multicolumn{5}{|l|}{ Clinical staging } \\
\hline Stages $1 / 11$ & 96.64 & 0.523 & 30.34 & 0.786 \\
\hline Stages 111/ IV & 96.27 & & 19.59 & \\
\hline \multicolumn{5}{|l|}{ Histologic grading } \\
\hline Well-differentiated & 96.08 & 0.906 & 25.02 & 0.791 \\
\hline Moderately/ poorly differentiated & 96.46 & & 29.86 & \\
\hline
\end{tabular}

poorly differentiated tumors (64.3\%) were observed in patients in stages III and IV ( $p=0.093)$. Median percentages of positivity for GLUT-1 and GLUT-3 are summarized in Table 2.

\section{Analysis of Immunostaining}

All cases of LLSCC were positive for GLUT-1 and GLUT-3. With respect to the pattern of staining, most tumors (70\%) exhibited a predominantly peripheral staining for GLUT1 in nests, sheets and islands of neoplastic cells. Strong GLUT-1 immunostaining was especially evident in areas of necrosis. In central areas of the tumor islands, GLUT-1 immunoexpression was mainly weak or absent, particularly in keratinization foci. In contrast, staining for GLUT-3 was predominantly central in nests, sheets and islands of neoplastic cells in most LLSCCs (72.5\%).

A high percentage of cytoplasmic and/or membrane staining for GLUT-1 was observed at the deep invasive front (Fig. 1A) and in the tumor core (Fig. 1B) of metastatic and non-metastatic tumors. However, the non-parametric Mann-Whitney test revealed no statistically significant difference between groups (Table 2). In all tumors, the percentage of GLUT-3-positive cells was much lower than that of GLUT-1-positive cells. In addition, the percentage of cytoplasmic and/or membrane staining for GLUT-3 at the deep invasive front was similar in metastatic and non-metastatic tumors (Fig. 1C) $(p=0.482)$ (Table 2). In the tumor core, the percentage of cytoplasmic and/or membrane staining for GLUT3 was higher in non-metastatic tumors than in metastatic tumors (Fig. 1D), but the difference was not significant ( $p=0.499$ ) (Table 2 ).

With respect to clinical stage, a high percentage of cytoplasmic and/or membrane staining for GLUT-1 at the deep invasive front and in the tumor core was observed in early-stage (stages I/II) and advanced tumors (stages III/IV). Statistical analysis showed no significant difference between groups (Table 2). Cytoplasmic and/or membrane staining for GLUT-3 at the deep invasive front was similar in early-stage (stages $\mathrm{I} / \mathrm{II}$ ) and advanced tumors (stages III/IV) ( $p=0.892)$ (Table 2). In the tumor core, the percentage of cytoplasmic and/or membrane staining for GLUT-3 was higher in early-stage tumors (stages I/II) when compared to advanced tumors (stages III/IV), but the difference was not statistically significant ( $\mathrm{p}=0.786$ ) (Table 2 ).

Analysis according to histological grade at the invasive front showed a predominance of cytoplasmic and/or membrane staining for GLUT-1 at the deep invasive front in both low-grade and 
high-grade tumors (Fig. 2A). The non-parametric MannWhitney test revealed no statistically significant difference between groups ( $p=0.447$ ) (Table 2). Cytoplasmic and/or membrane staining for GLUT-3 at the deep invasive front was similar in low-grade and high-grade tumors (Fig. 2B) $(\mathrm{p}=0.384)$ (Table 2).

Tumors classified as well-differentiated and moderately/ poorly differentiated by the $\mathrm{WHO}$ grading system exhibited a high percentage of cytoplasmic and/or membrane staining for GLUT- 1 in the tumor core (Fig. 2C). The non-parametric Mann-Whitney test revealed no statistically significant difference between groups $(p=0.906)$ (Table 2). The percentage of cytoplasmic and/or membrane staining for GLUT-3 in the tumor core was similar in well-differentiated and moderately/poorly differentiated tumors (Fig. 2D) ( $p=0.791$ ) (Table 2).

The non-parametric Wilcoxon signed rank test revealed a significantly higher percentage of GLUT-1-positive cells in comparison with GLUT-3-positive cells both in the deep invasive front $(p<0.001)$ and in the tumor core $(p<0.001)$ of LLSCCs. Spearman's correlation test revealed a significant positive correlation between the percentage of cytoplasmic and/or membrane staining for GLUT- 1 at the deep invasive front and in the tumor core $(r=0.679 ; p<0.001)$. Similarly, there was a positive correlation between the percentage of cytoplasmic and/or membrane staining for GLUT-3 at the deep invasive front and in the tumor core $(r=0.589$; $p<0.001$ ).

\section{Discussion}

Malignant neoplastic cells exhibit an altered metabolism which is characterized by the increased absorption and utilization of glucose $(5,7,8)$. This phenomenon can be explained by several mechanisms, including the adaptation of cells to the hypoxic tumor microenvironment. Tumor hypoxia is caused by factors such as rapid tumor growth, the inability of angiogenesis to accompany tumor development, disorganized vascular growth resulting in ischemic areas,
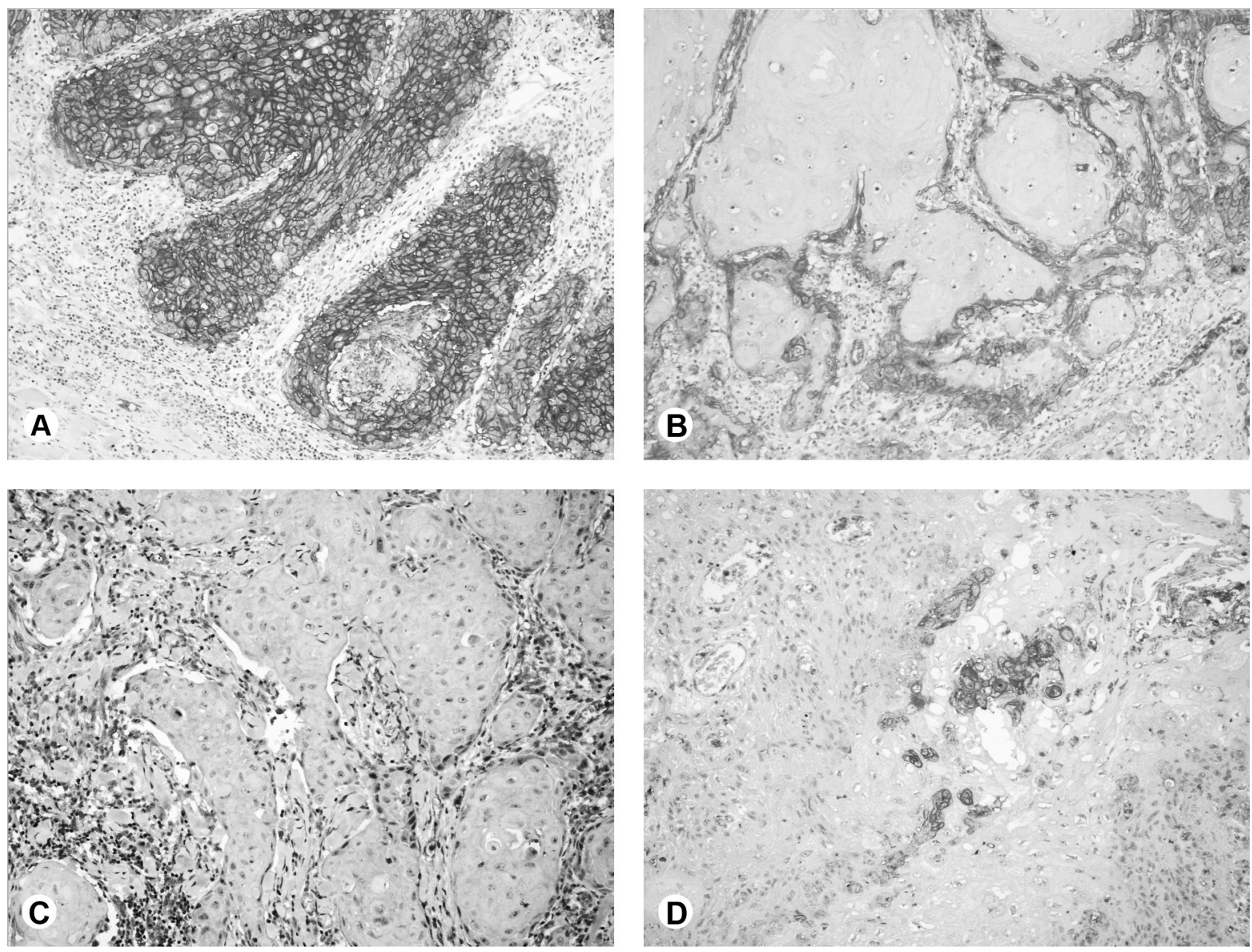

Figure 1. A: High percentage of staining for GLUT-1 in the invasive front of metastatic LLSCC (Advance, 100x). B: Predominantly peripheral staining for GLUT-1 in the tumor core of non-metastatic LLSCC (Advance, 200x). C: Low percentage of staining for GLUT-3 in the invasive front of nonmetastatic LLSCC (Advance, 200x). D: Predominantly central staining for GLUT-3 in the tumor core of metastatic LLSCC (Advance, 200x). 
and an increased hydrostatic pressure inside the tumor that causes microvascular compression $(19,20)$. Therefore, the maintenance of tumor cell viability depends in part on the ability of these cells to perform anaerobic glycolysis (6).

Hypoxia is an important characteristic of solid tumors and advanced head and neck carcinomas and this condition is associated with a poor prognosis $(11,21)$. GLUT- 1 and GLUT-3 mediate glucose uptake by cancer cells, regulating energy metabolism, and have been related to the aggressive behavior of some tumors $(7,9,12,21)$. Few studies have investigated the expression of GLUT- 1 and GLUT-3 in OSCC $(4,10-13,22,23)$ and, to the authors' knowledge, there are no investigations on the immunoexpression of these glucose transporters in LLSCC. Important membrane/cytoplasmic immunoexpression of GLUT-1 has been demonstrated in OSCCs, particularly at the periphery of tumor islands, whereas significantly lower expression was observed in the center of the tumor $(8,10,11,13-15,22)$. Similar results were obtained in the present study, suggesting that GLUT-1 plays an important role in glucose uptake in LLSCCs.

According to Ayala et al. (15), the lack of immunoexpression of GLUT-1 in the central areas of tumor islands is a characteristic finding in well-differentiated OSCCs. On the other hand, poorly differentiated tumors exhibit a pattern of GLUT-1 immunoexpression described by the authors as antistromal, i.e., enhanced immunostaining in central and perinecrotic zones. Similarly, Oliver et al. (10) observed strong immunostaining for GLUT-1 in areas of necrosis in OSCCs. In the present study, despite the identification of strong GLUT-1 immunostaining in areas of necrosis, no significant differences in the expression of this protein were observed between tumors with different histological grades of malignancy $(p>0.05)$. These results suggest that the immunoexpression of this glucose transporter is not related to the degree of cell differentiation in LLSCCs. Supporting this suggestion, Eckert et al. (13) and Yamada et al. (23) found no significant association between histological grade of malignancy and
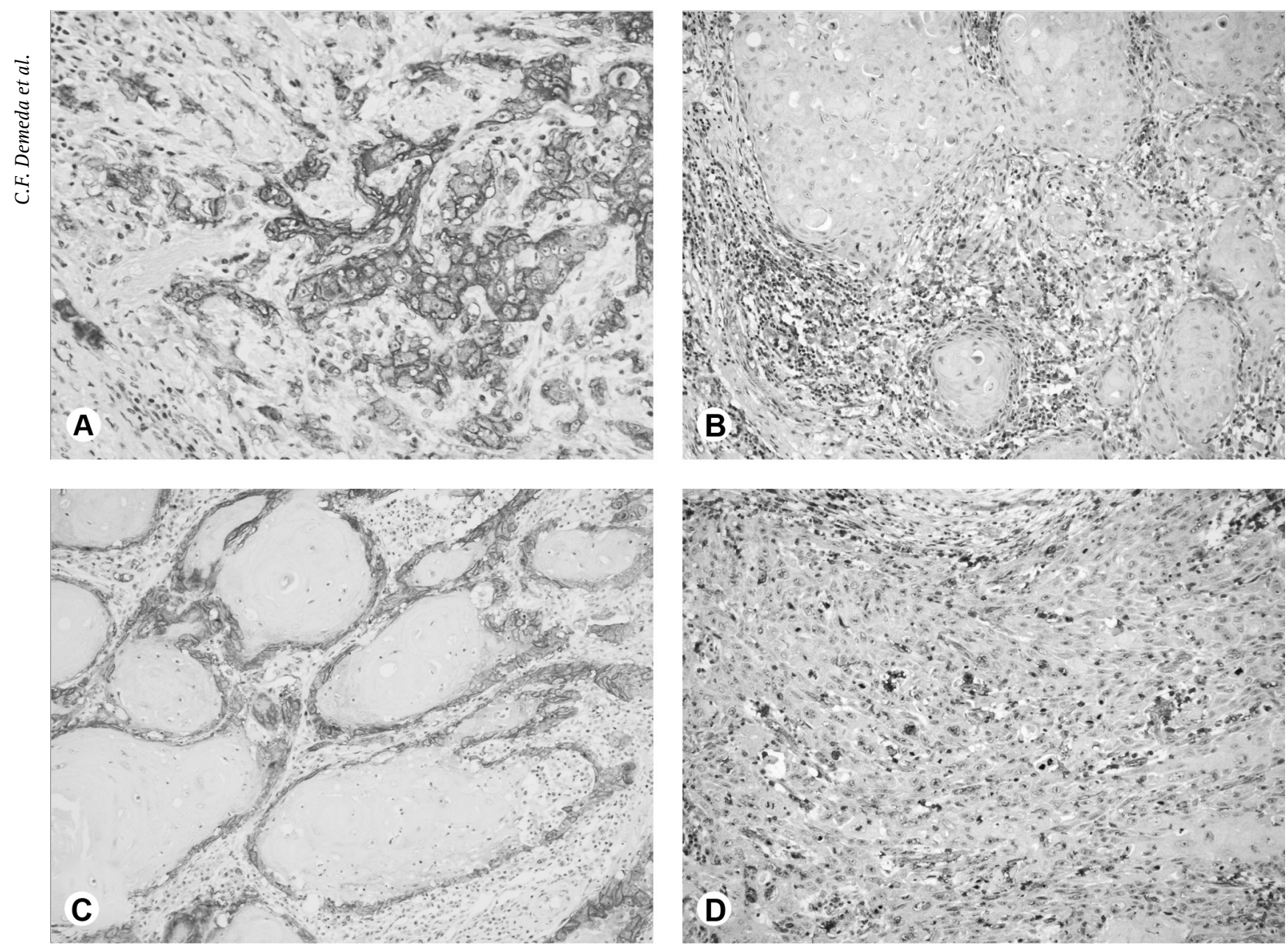

Figure 2. A: Immunoexpression of GLUT-1 in the invasive front of high-grade LLSCC (Advance, 400x). B: Immunoreactivity for GLUT-3 in the invasive front of low-grade LLSCC (Advance, 200x). (C) 1mmunoexpression of GLUT-1 in the tumor core of well-differentiated LLSCC (Advance, 200x). D: Immunoreactivity for GLUT-3 in the tumor core of moderately differentiated LLSCC (Advance, 400×). 
GLUT-1 immunoexpression in 0SCCs.

In the present study including cases of LLSCC, immunostaining for GLUT-3 was much lower than that for GLUT-1. In addition, GLUT-3 staining prevailed in central areas of tumor nests, islands and sheets. These findings suggest that the expression of GLUT-3 represents a secondary glucose uptake mechanism in LLSCCs, which is only important for central cells in tumor nests, islands and sheets. Similarly, Ayala et al. (15) observed GLUT3 immunostaining in only $30(21.1 \%)$ of 142 OSCCs analyzed, and Zhou et al. (24) found no immunoexpression of this glucose transporter in any of 38 head and neck carcinomas. On the other hand, Tian et al. (22) observed GLUT-3 immunostaining in 16 (84.2\%) of 19 OSCC cases analyzed. Despite the high percentage of positive cases, the authors found no significant association between the histological grade of the tumor and expression of this glucose transporter. Zhou et al. (24) also observed no association between expression of the GLUT-3 gene and the degree of cell differentiation in head and neck carcinomas. In the present study, GLUT-3 expression did not differ significantly between tumors with different histological grades of malignancy ( $p>0.05)$, suggesting that, as observed for GLUT-1, immunoexpression of GLUT-3 is not related to the degree of cell differentiation in LLSCCs.

A positive correlation was observed between the percentage of GLUT-1 immunoexpression at the invasive front and in the center of LLSCCs. Similar results were obtained for GLUT-3. Taken together, these findings suggest that, in LLSCC, increased glycolytic metabolism is not restricted to neoplastic cells at the tumor-host interface, a site where several important molecular events occur that are intimately related to enhanced cell metabolism, including cell proliferation and the secretion of proteolytic enzymes (17). This increased cell metabolism at the invasive front may contribute to increase hypoxia in central areas of LLSCCs. As part of the adaptation process to hypoxic conditions, central cells of the tumor increase the expression of GLUT- 1 and -3 and, consequently, glucose uptake and glycolytic metabolism.

Studies have shown an association between the overexpression of GLUT-1 in OSCCs and presence of lymph node metastasis $(10-12)$, episodes of recurrence $(10,14)$ and lower patient survival $(4,13-15)$, suggesting an important relationship between the expression of this glucose transporter and patient prognosis. However, Ohba et al. (8) found no association between the immunoexpression of GLUT-1 in OSCCs and clinical stage or lymph node metastasis. Roh et al. (11) also observed no significant correlation between GLUT-1 immunoexpression and survival of patients with tongue carcinoma. In the study of Yamada et al. (23), expression of GLUT-1 was not significantly associated with tumor size or regional metastasis in patients with OSCCs. In the present investigation, GLUT-1 immunoexpression was not associated with any of the clinical parameters (regional lymph node metastasis and clinical stage), suggesting that this protein is not involved in the progression of LLSCCs.

With respect to GLUT-3, Ayala et al. (15) reported an association of the expression of this protein with advanced clinical stage of OSCC and lower disease-free survival rates. In contrast, Zhou et al. (24) showed that the expression of the GLUT-3 gene in head and neck carcinomas was associated with regional lymph node metastasis, but not with clinical stage of the tumor. Tian et al. (22) also found no association between GLUT-3 immunoexpression and clinical stage in OSCCs. In the present study, GLUT-3 immunoreactivity was low in LLSCCs. In addition, there was no association between the immunoexpression of this protein and regional lymph node metastasis or clinical stage. These results suggest that GLUT-3 plays only a minor role in glucose uptake in LLSCCs and is not involved in the progression of these tumors.

Therefore, the present results suggest that increased glucose uptake by neoplastic cells is not essential for the progression of LLSCC. However, it cannot be ruled out the possibility that subsequent events, such as the metabolism of glucose, contribute more significantly to tumor progression. Within this context, isoenzymes of the lactate dehydrogenase family, particularly lactate dehydrogenase 5 (LDH5), are important for anaerobic glycolysis. These enzymes convert pyruvate into lactate $(5,25)$. In a study including 191 cases of OSCC, Grimm et al. (25) showed that overexpression of LDH5 was associated with the presence of regional lymph node metastasis, advanced clinical stage, and lower tumor-specific survival. These findings highlight the need for studies investigating the effects of alterations in anaerobic glucose metabolism on the progression of LLSCCs.

In conclusion, the results of the present study suggest an important role of GLUT-1 in glucose uptake in LLSCCs. However, this protein does not seem to be involved in the progression of these tumors. On the other hand, expression of GLUT-3 may represent a secondary glucose uptake mechanism in LLSCCs, which is only important for central cells in tumor nests, islands and sheets.

\section{Resumo}

Este estudo objetivou avaliar a imunoexpressão dos transportadores de glicose 1 (GLUT-1) e 3 (GLUT-3) em carcinomas de células escamosas de lábio inferior (CCELI) metastáticos e não-metastáticos. Vinte CCELIs com metástase nodal regional e $20 \mathrm{CCELI}$ sem metástase foram selecionados. Foram analisados a distribuição da imunomarcação e o percentual de imunorreatividade para GLUT-1 e GLUT-3 no centro tumoral e no front de invasão tumoral. A maioria dos tumores (70\%) revelou marcação para GLUT-1 em áreas periféricas dos ninhos, lençóis e ilhas de células neoplásicas, ao passo que GLUT-3 revelou predomínio de marcação em 
áreas centrais $(72.5 \%)$. Um alto percentual de células positivas para GLUT-1 foi observado no front de invasão e no centro tumoral das lesões metastáticas e não-metastáticas $(p>0,05)$. 0 percentual de células positivas para GLUT-1 foi superior ao percentual de células positivas para GLUT-3, tanto no front de invasão $(p<0,001)$ quanto no centro tumoral $(p<0,001)$ dos CCELIs. Não foram observadas diferenças significativas no percentual de células positivas para GLUT-1 e GLUT-3 em relação à mestástase nodal, ao estádio clínico ou ao grau histológico de malignidade $(p>0,05)$. Em conclusão, os resultados do presente estudo sugerem um importante papel para GLUT-1 na absorção de glicose nos CCELIs, embora esta proteina não pareça estar envolvida na progressão destes tumores. Por outro lado, a expressão de GLUT-3 pode representar um mecanismo secundário para a absorção de glicose nos CCELIs.

\section{References}

1. Zini A, Czerninski R, Sgan-Cohen H. Oral cancer over four decades: epidemiology, trends, histology, and survival by anatomical sites. J Oral Pathol Med 2010;39:299-305.

2. Salgarelli AC, Sartorelli $F$, Cangiano A, Pagani R, Collini M. Surgical treatment of lip cancer: our experience with 106 cases. J Oral Maxillofac Surg 2009;67:840-845.

3. Gutiérrez-Pascual M, Vicente-Martín FJ, Fernández-Álvarez JG, MartínLópez R, Pinedo-Moraleda F, López-Estebaranz JL. Squamous cell carcinoma of the lip: a retrospective study of 146 patients. J Eur Acad Dermatol Venereol 2012;26:1116-1121.

4. Kunkel $M$, Moergel $M$, Stockinger $M$, Jeong $J H$, Fritz $G$, Lehr HA, et al.. Overexpression of GLUT- 1 is associated with resistance to radiotherapy and adverse prognosis in squamous cell carcinoma of the oral cavity. Oral Oncol 2007;43:796-803.

5. Ortega $A D$, Sánchez-Aragó $M$, Giner-Sánchez $D$, Sánchez-Cenizo L, Willers I, Cuezva JM. Glucose avidity of carcinomas. Cancer Lett 2009;276:125-135.

6. Pérez-Sayáns $M$, Suárez-Peñaranda JM, Pilar GD, Barros-Anqueira $F$, Gándara-Rey JM, Garcia-Garcia A. Hypoxia-inducible factors in OSCC. Cancer Lett 2011;313:1-8.

7. Macheda ML, Rogers S, Best JD. Molecular and cellular regulation of glucose transporter (GLUT) proteins in cancer. J Cell Pyshiol 2005;202:654-262.

8. Ohba $S$, Fujii $H$, Ito $S$, Fujimaki $M$, Matsumoto $F$, Furukawa $M$, et al.. Overexpression of GLUT-1 in the invasion front is associated with depth of oral squamous cell carcinoma and prognosis. J Oral Pathol Med 2010;39:74-78.

9. Ogane N, Yasuda M, Shimizu M, Miyazawa M, Kamoshida S, Ueda A, et al.. Clinicopathological implications of expressions of hypoxia-related molecules in esophageal superficial squamous cell carcinoma. Ann Diagn Pathol 2010;14:23-29.

10. Oliver RJ, Woodwards RT, Sloan P, Thakker NS, Stratford IJ, Airley RE. Prognostic value of facilitative glucose transporter Glut-1 in oral squamous cell carcinomas treated by surgical resection: results of EORTC Translational Research Fund studies. Eur J Cancer 2004;40:503507.

11. Roh JL, Cho KJ, Kwon GY, Ryu CH, Chang HW, Choi SH, et al.. The prognostic value of hypoxia markers in T2-staged oral tongue cancer.
Oral Oncol 2009:45:63-68.

12. Kondo $Y$, Yoshikawa $K$, Omura $Y$, Shinohara $A$, Kazaoka $Y$, Sano J, et al.. Clinicopathological significance of carbonic anhydrase 9, glucose transporter-1, Ki-67 and p53 expression in oral squamous cell carcinoma. Oncol Rep 2011;25:1227-1233.

13. Eckert AW, Lautner MH, Schütze A, Taubert $H$, Schubert J, Bilkenroth U. Coexpression of hypoxia-inducible factor-1区 and glucose transporter-1 is associated with poor prognosis in oral squamous cell carcinoma patients. Histopathology 2011;58:1136-1147.

14. Kunkel $M$, Reichert $T E$, Benz $P$, Lehr $H A$, Jeong JH, Wieand $S$, et al.. Overexpression of Glut-1 and increased glucose metabolism in tumors are associated with a poor prognosis in patients with oral squamous cell carcinoma. Cancer 2003;97:1015-1024.

15. Ayala FR, Rocha RM, Carvalho KC, Carvalho AL, da Cunha IW, Lourenço SV, et al.. GLUT1 and GLUT3 as potential prognostic markers for oral squamous cell carcinoma. Molecules 2010;15:2374-2387.

16. Cardesa A, Gale N, Nadal A, Zidar N. Squamous cell carcinoma. In: Barnes L, Eveson JW, Reichart P, Sidransky D, editors. World Health Organization classification of tumours. Pathology and genetics of head and neck tumours. Lyon: IARC Press; 2005. p.118-121.

17. Bryne M. Is the invasive front of an oral carcinoma the most important area for prognostication? Oral Dis 1998:4:70-77.

18. Silveira EJ, Godoy GP, Lins RD, Arruda M de L, Ramos CC, Freitas R de $A$, et al.. Correlation of clinical, histological, and cytokeratin profiles of the squamous cell carcinoma of the oral tongue with prognosis. Int J Surg Pathol 2007;15:376-383.

19. Kondoh H. Cellular life span and the Warburg effect. Exp Cell Res 2008:314:1923-1928.

20. Rademakers SE, Lok J, van der Kogel AJ, Bussink J, Kaanders JH. Metabolic markers in relation to hypoxia staining patterns and colocalization of pimonidazole, HIF-1区, CAIX, LDH-5, GLUT-1, MCT1 and MCT4. BMC Cancer 2011;11:167.

21. Eckert AW, Kappler M, Schubert J, Taubert H. Correlation of expression of hypoxia-related proteins with prognosis in oral squamous cell carcinoma patients. Oral Maxillofac Surg 2012;16:189-196.

22. Tian $M$, Zhang $H$, Nakasone $Y$, Mogi $K$, Endo K. Expression of Glut-1 and Glut-3 in untreated oral squamous cell carcinoma compared with FDG accumulation in a PET study. Eur J Nucl Med Mol Imaging 2004;31:5-12.

23. Yamada $T$, Uchida $M$, Kwang-Lee $K$, Kitamura $N$, Yoshimura $T$,

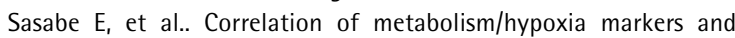
fluorodeoxyglucose uptake in oral squamous cell carcinoma. Oral Surg Oral Med Oral Pathol Oral Radiol 2012;113:464-471.

24. Zhou S, Wang S, Wu Q, Fan J, Wang 0. Expression of glucose transporter-1 and -3 in the head and neck carcinoma - the correlation of the expression with the biological behaviors. ORL J Otorhinolaryngol Relat Spec 2008;70:189-194.

25. Grimm M, Alexander D, Munz A, Hoffmann J, Reinert S. Increased LDH5 expression is associated with lymph node metastasis and outcome in oral squamous cell carcinoma. Clin Exp Metastasis 2013;30:529-540.

Received April 10, 2014 Accepted September 15, 2014 